
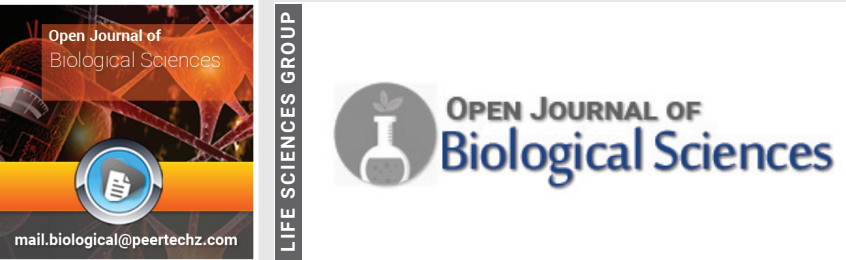

\title{
Pineapple juice preservation by pulsed electric field treatment
}

\section{Abu Yousuf ${ }^{1 *}$, Md Anisur Rahman', M Rakib Uddin², Md Mozammel Hoque ${ }^{3}$, A S M Sayem ${ }^{3}$, Md Shahadat Hossain', Md Shah Ali ${ }^{3}$, Md Sazzad Ahmed ${ }^{1}$ and Mushaida Haque ${ }^{1}$}

'Department of Chemical Engineering and Polymer Science, Shahjalal University of Science and Technology, Bangladesh

2Department of Engineering, Universita degli Studi di Napoli "Parthenope", Napoli, Italy

${ }^{3}$ Department of Food Engineering and Tea Technology, Shahjalal University of Science and

Technology, Bangladesh
Received: 20 December, 2019

Accepted: 26 February, 2020

Published: 27 February, 2020

${ }^{*}$ Corresponding author: Abu Yousuf, Department of Chemical Engineering and Polymer Science, Shahjalal University of Science and Technology, Bangladesh, Email: ayousufcep@yahoo.com; ayousuf-cep@sust.edu

Keywords: Pineapple juice; Pulsed electric field; Bioactive compound; Total phenolic content; Antioxidant activity

https://www.peertechz.com

Check for updates

\begin{abstract}
The effect of pulsed electric field (PEF) treatment on pineapple juice, applied in a batch system, was studied in terms of change in microbial community, bioactive compounds, and antioxidant capacity. Among the bioactive compounds, total phenolic content (TPC), flavonoid, ascorbic acid, and $\beta$-carotene content were evaluated. The results were monitored over a 10 days of storage at $-20^{\circ} \mathrm{C}$ and compared with that of untreated juice sample. A PEF device-designed and fabricated in laboratory-was used for this purpose and the applied electric field strength were $9 \mathrm{kV} / \mathrm{cm}, 11 \mathrm{kV} / \mathrm{cm}$, and $13 \mathrm{kV} / \mathrm{cm}$ at a frequency of $100 \mathrm{~Hz}$. Highest microbial inactivation was observed at $13 \mathrm{kV} / \mathrm{cm}$ field intensity, which was the greatest possible field strength supplied by the PEF system. During storage, microbes grew in PEF treated juice, though at a slower pace than the untreated one, since the applied field intensity was far short of critical value to inactivate them entirely. All the bioactive compounds experienced a slight reduction in treated juice. Over time, the TPC and $\beta$-carotene of treated juice reduced at a slower rate than the untreated juice, whereas flavonoid and ascorbic acid content diminished at a similar rate. The treated juice lost its antioxidant capacity at a lower speed than the untreated one, though it did not change immediately after PEF treatment. Therefore, with higher electric field applied, PEF processing may be an effective preservation technique for pineapple juice in achieving sustainable shelf-life with uncompromised nutritious and ant-oxidant values over long term storage.
\end{abstract}

\section{Introduction}

Being the source of essential minerals, vitamin, and diversity to diet, the demand for consumption of fruits is ever increasing. Among them, many fruits are reach in phenolic compounds, carotenoids, and vitamin $\mathrm{C}$ or ascorbic acid, which have huge antioxidant potential and whose intakes are highly encouraged due to their role in reducing cancer, cardiovascular, and neurological diseases [1]. Since the availability of fruits varies from place to place and season to season, consumption of their preserved version has been practiced. One of the best ways to preserve fruit is to store it in juice form. But long term preservation has been a growing concern since the nutritious quality and sensory attributes can be impaired by microorganisms, spoilage enzymes, and undesirable chemical reactions [2]. Moreover, the increasing consciousness about diet and health issues goaded consumer into searching for food products which is of superior nutritional and sensory quality, durable shelf life, and requires minimal processing [3]. To address these issues several treatment methods have been applied among which thermal pasteurization is frequently pronounced. Although thermal processing appear to have extended the shelf life of several juices, it has been demonstrated in several studies that considerable deterioration in sensory, nutritional, and biochemical compounds occur which are very heat sensitive $[4,5]$. In response to this limitation, researchers have come up with Pulsed Electric Field (PEF) as a nonthermal treatment process which has been proved to decrease microbes and spoilage enzymes to an extent, comparable to that by thermal processes, without sacrificing flavor, color and bioactive compounds [6].

PEF process involves the application of short burst of electric field to a sample placed between two electrodes which causes 
permeabilization-may be reversible or irreversible depending on process parameters-of membrane [7]. The most commonly accepted theory behind cell permeabilization is that under the exposure of external electric field, free charges accumulate on both side of the membrane resulting a transmembrane potential and when the induced membrane potential exceeds a critical field strength, membrane disruption or destruction occurs [8]. The efficiency of this process was found to be strongly dependent on field intensity, pulse duration, treatment time, type of microbial stain, and properties of the sample under investigation [9]. Though Sale and Hamilton first experimented the lethal effect of PEF on microbes in 1967 [10], the applicability of PEF in food processing is a recent concept. Various researchers have been proved successful in applying PEF process in preserving several food products, such as milk [11], sugarcane juice [10], strawberry juice [12], orange juice [13], apple juice [5], grape juice [14] etc.

Pineapple (Ananas comosus) is a popular tropical fruit, mainly consumed as juice, has a growing demand all over the world due to its very pleasant aroma and flavor [15]. Several phytochemicals, such as phenolic compounds, ascorbic acid, and carotenoid are regarded as beneficial nutrients in pineapple juice [16]. The world-wide total pineapple production is estimated between 16 to 19 million tons [17]. In Bangladesh, according to Bangladesh Bureau of Statistics (BSS), the pineapple production was 218.6 thousand metric ton during the fiscal year 2010-11. So to make this huge production marketable without altering bioactive content and anti-oxidant capacity, a facile processing of pineapple juice is necessary. Typically, thermal processing has been in practice, but the aforementioned limitations of this process welcome $\mathrm{PEF}$ as a viable alternative to treat pineapple juice for providing stable shelf-life. Though PEF has been successfully applied in treating different juices, surprisingly a few or no study has been conducted on PEF treatment of pineapple juice.

Therefore, this present study was directed to investigate the effects of PEF processing on inactivation of endogenous microorganisms in pineapple juice as well as on different bioactive compounds, such as total phenolic, flavonoid content, ascorbic acid, $\beta$-carotene, and their role in antioxidant capacity of the juice. The change of these experimental parameters before and after treatment over storage of 10 days had also been compared. To conduct these studies a laboratory scale PEF device was built.

\section{Materials and methods}

\section{Preparation of juice}

Fresh pineapples were purchased from a local retail grocery store-Agora (Sylhet branch, Bangladesh). The as-received pineapples were washed with tap water, peeled off and sliced into small pieces $(3-5 \mathrm{~mm})$, and then again washed with distilled water. After that, these washed pineapple slices went through a domestic juice extractor (Miyako BL-302) to obtain fresh juice. The prepared juice was then filtered using a cotton filter cloth and the filtrate (clear juice) was then centrifuged (Model-316, Gyrozen, Korea) at $3000 \mathrm{rpm}$ for $15 \mathrm{~min}$ to discard the remaining pulp and any solid particles. The supernatant was, after that, put in several sterilized (at $121^{\circ} \mathrm{C}$ for $30 \mathrm{~min}$ ) $250 \mathrm{ml}$ polypropylene bottles. These bottles were stored at $-20{ }^{\circ} \mathrm{C}$ until treatment when they were left to thaw at ambient temperature.

\section{Pulsed Electric Field (PEF) treatment}

A laboratory scale PEF device was designed and constructed in Shahjalal University of Science and Technology (Sylhet, Bangladesh). The system consisted of four sections, such as power supply section, pulse generation and computational control section, high voltage level shifter section, and a reactor section. A simple cuvette served the purpose of reactor in which two copper electrodes were at an electrode distance of $2 \mathrm{~mm}$ and the sample volume was $1 \mathrm{ml}$. The device was operated in batch mode and the applied electric field strength were $9 \mathrm{kV} /$ $\mathrm{cm}, 11 \mathrm{kV} / \mathrm{cm}$, and $13 \mathrm{kV} / \mathrm{cm}$ with square waveform pulse at a frequency of $1000 \mathrm{~Hz} .13 \mathrm{kV} / \mathrm{cm}$ was the highest achievable field strength of the fabricated PEF device and the treatment time was $1 \mathrm{~ms}$.. The PEF processed juice was poured into sterilized $250 \mathrm{ml}$ polypropylene bottles and stored at $-20^{\circ} \mathrm{C}$ until further analysis.

\section{Microbial count analysis}

Plate Count Method was employed for the examination of total number of viable microbes present in juice sample before and after PEF treatment. Juice samples, before and after treatment, were adequately diluted and $1 \mathrm{ml}$ samples were pipetted out on to petri dish equipped with nutrient media. The nutrient media was comprised of $0.5 \%$ peptone, $0.3 \%$ beef extract, $0.5 \% \mathrm{NaCl}, 1.5 \%$ agar with respect to distilled water and was sterilized in an autoclave (UTKBS- $50 \mathrm{~V}$, mrclab, China) at $121{ }^{\circ} \mathrm{C}$ for $30 \mathrm{~min}$. The culture media and diluted sample were mixed well by a gentle swirling motion. The petri dishes were then allowed to solidify under incubation at $37^{\circ} \mathrm{C}$ for 72 hours. After incubation, Colony Forming Units (CFU) were counted using a digital colony counter (J-3 colony counter, SCO Engineering, Germany).

\section{Determination of total phenolic content}

Total Phenolic Content (TPC) in the sample extract was assessed by spectrophotometric method using FolinCiocalteau's assay [18], with slight alternation. To quantify the TPC, $20 \mu \mathrm{L}$ of each juice extract was poured in test tube followed by the addition of $1.58 \mathrm{~mL}$ of distilled water and then $100 \mu \mathrm{L}$ of Folin-Ciocalteau reagent and mixed thoroughly. After $8 \mathrm{~min}$, $300 \mu \mathrm{L}$ of sodium carbonate was added to the mixture and the samples were vortexed (VM-2000, Digisystem Laboratory Instruments Inc.,Taiwan) immediately and left for incubation in the dark for $30 \mathrm{~min}$ at $40 \mathrm{C}$. The absorbance of the samples were then measured at $765 \mathrm{~nm}$ in a UV-Vis spectrophotometer (UV-1800, Shimadzu Scientific Instruments, Japan). A calibration curve was prepared using standard solution of gallic acid, and the results of TPC were expressed as mg of Gallic Acid Equivalents (GAE) per $100 \mathrm{~g}$ of sample.

\section{Determination of total flavonoid content}

Total flavonoid content (TFC) of the juice extract was determined by a modified method described elsewhere [19]. 
Quercetin was used as standard. $0.5 \mathrm{~mL}$ of the standard solutions diluted in $80 \%$ ethanol or sample juice extract were mixed with $1.5 \mathrm{~mL}$ of $95 \%$ ethanol, $0.1 \mathrm{~mL}$ of $10 \%$ aluminumtrichloride solution, $0.1 \mathrm{~mL}$ of $1 \mathrm{M}$ potassium-acetate, and $2.8 \mathrm{~mL}$ of deionized water. After that the mixture was left for incubation at room temperature for $40 \mathrm{~min}$ and then the absorbance of the reaction mixture was measured at $415 \mathrm{~nm}$ against a blank of distilled water, instead of $10 \%$ aluminumtrichloride solution, in a UV-Vis spectrophotometer. Results were expressed as $\mathrm{mg}$ of Quercetin Equivalent ( $\mathrm{QE})$ per $100 \mathrm{~g}$ of sample.

\section{Determination of ascorbic acid}

The amount of ascorbic acid in juice sample was measured by spectrophotometric method based on the ability of standard ascorbic acid and ascorbic acid in sample to decolorize 2,6-dichlorophenol-indophenol dye solution as described by S. Ranganna [20]. Briefly, for sample preparation, $10 \mathrm{ml}$ of each juice sample were transferred to $100 \mathrm{ml}$ volumetric flask and the remaining was filled with $2 \%$ metaphosphoric acid. Dye solution was prepared by dissolving 2,6-dichlorophenolindophenol in distilled water along with sodium bicarbonate. Ascorbic acid was used as standard and the solution was prepared by dissolving ascorbic acid in $2 \%$ metaphosphoric acid. $10 \mathrm{ml}$ of dye solution was added to $5 \mathrm{ml}$ of standard ascorbic acid solution of known concentration or sample juice extract and then they were mixed thoroughly. After that, the absorbance of these mixtures were measured at 518nm against a blank consisting of $5 \mathrm{ml} \mathrm{2 \%}$ metaphosphoric acid and $10 \mathrm{ml}$ of distilled water. Finally the ascorbic acid content in the sample was calculated by the following equation:

mg of ascorbic acid/100g of sample

Ascorbic acid content $\times$ volume made up $\times 100$

$\mathrm{ml}$ of solution taken for estimation $\times 1000 \times$ weight of sample taken

\section{Determination of $\beta$-carotene}

Biswas and his fellow researchers [21] developed a simple and reliable UV-Vis spectrophotometric method for the determination of $\beta$-carotene in different food categories and current study employed the same for determining $\beta$-carotene in pineapple juice. To extract $\beta$-carotene from juice sample, $1 \mathrm{~g}$ of thawed juice was mixed with $5 \mathrm{ml}$ of chilled acetone in a test tube and kept in shaking for $15 \mathrm{~min}$. Then it was vortexed at high speed for $10 \mathrm{~min}$ and later it was centrifuged at 4000 rpm (1730R, Gyrozen, Korea) for 10min. The supernatant was separated and transferred to a beaker and the remaining compound was re-extracted adding $5 \mathrm{ml}$ chilled acetone followed by centrifugation and separation of supernatant as before. Both supernatant was filtered using a filter paper and subjected to a UV-Vis spectrophotometer for measuring absorbance at $449 \mathrm{~nm}$ wavelength which was then compared to a standard curve to calculate the $\beta$-carotene content in the juice (mg/100 mg juice). A standard curve of $\beta$-carotene was made using standard stock solution of $\beta$-carotene prepared by dissolving the standard in acetone. Determination of antioxidant activity by 2,2-diphenyl-1-
picril-hidrazil (DPPH) assay

The antioxidant activity of pineapple juice was measured by its inhibition capability of 2,2-diphenyl-1-picril-hidrazil (DPPH) radicals using a slightly altered method of BrandWilliams et al. [22]. $100 \mu \mathrm{L}$ of each sample extracts was added to $1.4 \mathrm{~mL} \mathrm{DPPH}$ radical solution $\left(10^{-4} \mathrm{M}\right)$ in methanol which were allowed to react for $30 \mathrm{~min}$ at dark. Then the absorbance of reaction mixture were measured at $517 \mathrm{~nm}$ against blank (100 $\mu \mathrm{L}$ methanol instead of sample extract) using a UV-Vis spectrophotometer. The results were expressed in terms of radical scavenging activity using the following equation:

Radical scavenging activity $(\%)=\frac{\mathrm{A}_{0}-\mathrm{A}_{\mathrm{s}}}{\mathrm{A}_{0}} \times 100$

Where, $A_{o}$ is absorbance of control blank and $A_{s}$ is absorbance of sample extract.

\section{Result and discussion}

\section{Effect of PEF treatment on microbial count}

The total microbial count in pineapple juice immediately after PEF treatment and after a storage time of 5days and 10 days at different electric field strength, ranging from $9 \mathrm{kV} /$ $\mathrm{cm}$ to $13 \mathrm{kV} / \mathrm{cm}$, was studied and compared with that of the untreated juice-results of which are shown in Figure 1.

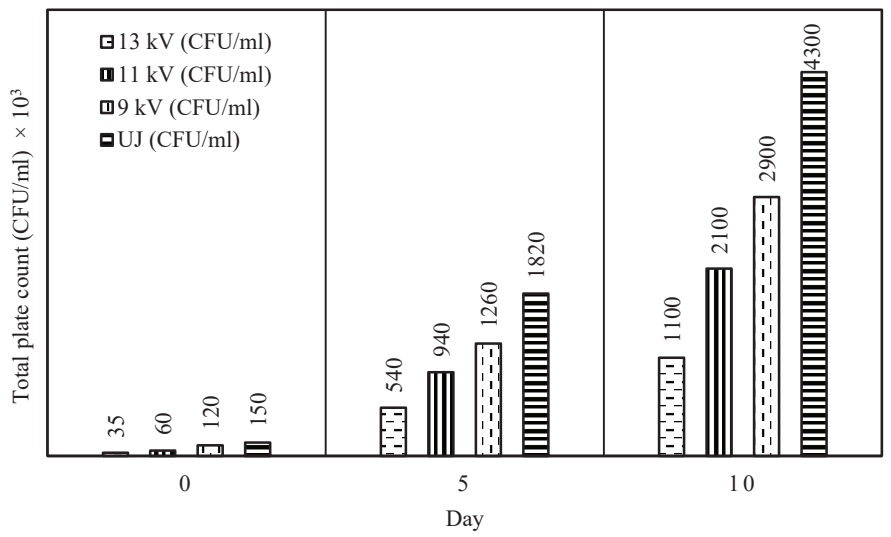

Figure 1: Total plate count of PEF treated (at $9 \mathrm{kV} / \mathrm{cm}, 11 \mathrm{kV} / \mathrm{cm}$, and $13 \mathrm{kV} / \mathrm{cm}$ ) and untreated juice ( $\mathrm{UJ}$ ) over different storage time ( 0 day, 5 days, and 10 days).

As can be seen that the total plate count dropped from 150 $\times 10^{3} \mathrm{CFU} / \mathrm{ml}$ to $120 \times 10^{3} \mathrm{CFU} / \mathrm{ml}$ after PEF treatment at $9 \mathrm{kV} /$ $\mathrm{cm}$ strength and it reached the lowest value of $35 \times 10^{3} \mathrm{CFU} / \mathrm{ml}$ for a treatment intensity of $13 \mathrm{kV} / \mathrm{cm}$ which was the highest achievable field strength obtained by our fabricated PEF device. Thus an increase in electric field intensity resulted in higher microbial reduction which may be attributed to greater number of permeated cells at higher field strength $[8,23]$. Nevertheless, a considerable amount of microbes survived within the applied electric field range which, may be, were below a threshold value for achieving a critical transmembrane potential value of $1 \mathrm{~V}$ required for membrane breakdown [24]. Moreover, the orientation of microbial cell and their agglomeration and interaction with insulating particles may impair the critical membrane field strength experienced by the cells for a given field strength and make them immune to applied electric 
field [9]. However, after a storage time of 5 and 10 days, the total microbial count in treated juice was found to increase noticeably, though the rate decreased with increasing treatment intensity from $9 \mathrm{kV} / \mathrm{cm}$ to $13 \mathrm{kV} / \mathrm{cm}$ and were significantly lower than that of the untreated one. This is because at these low intensity, below a critical value, inactivation was partially due to reversible permeabilization [25], or sub lethal damage of cell which, with time, may survive and contribute to increase in total plate count during storage leading to unsatisfactory shelf-life [23]. For this reason, Toefl and his co-workers [9] suggested an electric field strength in the range of 20 to $50 \mathrm{kV} /$ $\mathrm{cm}$ for ensuring effective microbial inactivation. Hence, it can be inferred that an increased treatment intensity beyond the critical value would guarantee a longer shelf-life; a shelf-life of more than 67 days for PEF treated apple juice at $34 \mathrm{kV} / \mathrm{cm}$ [26] and 12 weeks for PEF treated pomegranate juice at $38 \mathrm{kV} /$ $\mathrm{cm}$ [7] bear the testimony of this assertion.

\section{Effect on total phenolic content}

The presence of phenolic compounds, one of the most widely occurring groups of phytochemicals, in fruit juice are of considerable interest due to their antioxidant properties which may be ascribed to their ability to scavenge free radicals, donate hydrogen atoms, electrons, or chelate ions [27,28]. In this present study, the TPC of untreated and PEF treated juice at different storage time were determined by Folin-Ciocalteu assay, and the findings are reported in Figure 2.

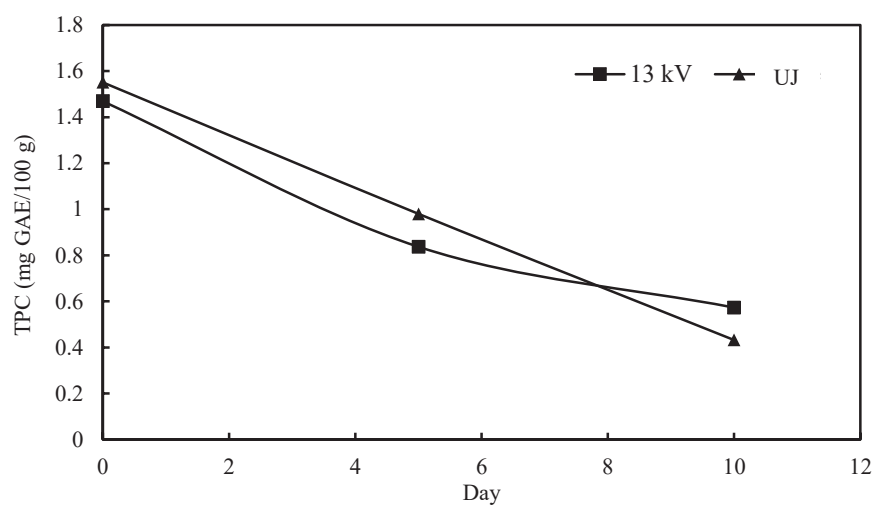

Figure 2: Total phenolic content (TPC) of PEF treated $(13 \mathrm{kV} / \mathrm{cm})$ juice and untreated juice (UJ) with respect to time.

It can be depicted that the TPC of treated juice slightly reduced from that of the untreated one. A similar observation was reported by Zhang and his fellow researchers [29], during PEF treatment of longan juice at $32 \mathrm{kV} / \mathrm{cm}$. However, with increasing storage time both PEF treated and untreated juice were found to decrease in TPC and after 7 days of storage the loss of TPC of untreated juice was more than the treated one. The depletion of TPC over storage might be a result of oxidation of these compounds and polymerization reaction with proteins [30] and is in accordance with previous studies [12]. It has been reported that polyphenol oxidase and peroxidase are responsible for phenolic compound oxidation [31]. PEF treatment may hindered these enzymes' activity which resulted in lower TPC loss than untreated juice during storage.

\section{Effect on flavonoid content}

Flavonoids generally account for more than half of the over eight thousand different phenolic compounds [27]. This group comprises, but not limited to, anthocyanins, Xavonols, Xavan-3-ols, Xavonones and Xavononols [32]. The change of total flavonoid content of fresh and PEF treated pineapple juice during storage is shown in Figure 3.

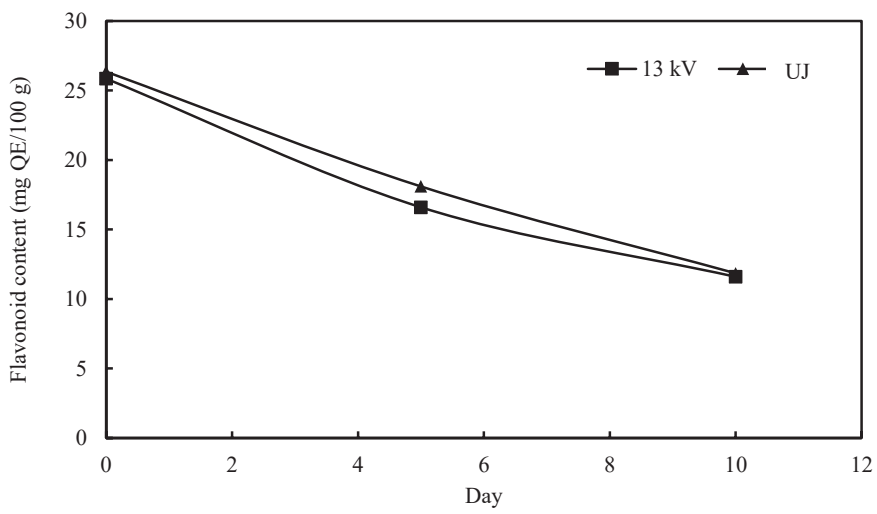

Figure 3: Flavonoid content of PEF treated $(13 \mathrm{kV} / \mathrm{cm})$ and untreated juice (UJ) at different days.

The flavonoid content of fresh and treated juice at day 0 were considerably similar. The content of these bioactive compounds diminished, nearly at the same rate, from 26 to $12 \mathrm{mg} \mathrm{QE} / 100 \mathrm{~g}$ within 10 days storage for both treated and untreated juice. Result of other published studies support this behavior of flavonoid content over storage [33]. This decrease in total flavonoid content was may be due to depletion of plg3-glu and plg-3-rut content and, in turn, total anthocyanin of juices, with storage time irrespective of the treatment applied [12]. A previous study attributed indirect oxidation of phenolic quinons generated by polyphenol oxidase to degradation of anthocyanin [34]. In general, no significant difference in flavonoid content was observed between fresh and treated juice.

\section{Effect on ascorbic acid}

From the point of nutritional point of view, ascorbic acid, also known as vitamin $\mathrm{C}$, is an essential nutrient for human body which help to form collagen, cartilage, muscle and blood vessels, and also facilitate iron adsorption [35]. Pineapple has been described to contain much less amount of ascorbic acid compared to that of citrus fruits [16]. The effect of PEF processing on ascorbic acid in pineapple juice for a storage duration of 10 days is exhibited in Figure 4.

It is obvious that PEF treatment reduced ascorbic acid in pineapple juice slightly, by nearly $1.5 \mathrm{mg} / 100 \mathrm{~g}$, a behavior also shown by other researchers in treating different fruits $[29,36,37]$. The concentration of ascorbic acid in PEF processed and untreated juice dwindled gradually, at the same pace, with storage time. Vitamin $\mathrm{C}$ is vulnerable to enzyme-catalyzed oxidation, such as ascorbate oxidase and peroxidase [38], which may cause the reduction of ascorbic acid during storage. 
Odriozola-Serrano and co-workers [12], studied the influence of PEF on vitamin $\mathrm{C}$ of strawberry juice during storage and the result encouragingly showed clear concordance with the finding of this study.

\section{Effect on $\beta$ carotene}

Carotenoids are among the most abundant phytonutrients found in fruits and vegetables, and on average about $60 \%$ of the vitamin $A$ is estimated to stem from carotenoids [39]. $\beta$ carotene is one of the carotenoids which have vitamin A activity [40]. Hence, the impact of PEF treatment and subsequent storage on $\beta$ carotene content in pineapple juice was investigated and the outcomes are portrayed in Figure 5. The concentration of $\beta$ carotene was lower in PEF treated juice than in untreated juice at day 0 and then for both sample it decreased with storage time. Compared to PEF treated juice, the rate of $\beta$ carotene depletion was higher in the juice left untreated. The same relationship between carotenoids with vitamin A activity and storage time was observed during PEF treatment of orange juice [41]. $\beta$ carotene are highly unsaturated molecule due to presence of polyene in their chain structure which make them prone to oxidation or isomerization responsible for their degradation with storage time [42]. May be PEF treatment inhibited the activity of some enzymes which are responsible for catalyzing oxidation or isomerization of $\beta$ carotene.

\section{Effect on DPPH radical scavenging capacity}

Antioxidant capacity of pineapple juice measured through

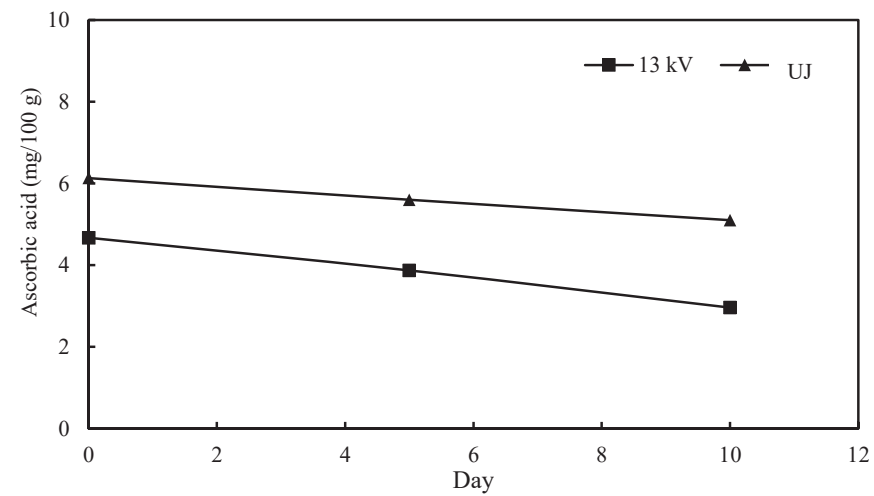

Figure 4: Ascorbic acid content of PEF treated $(13 \mathrm{kV} / \mathrm{cm})$ and untreated juice (UJ) during storage.

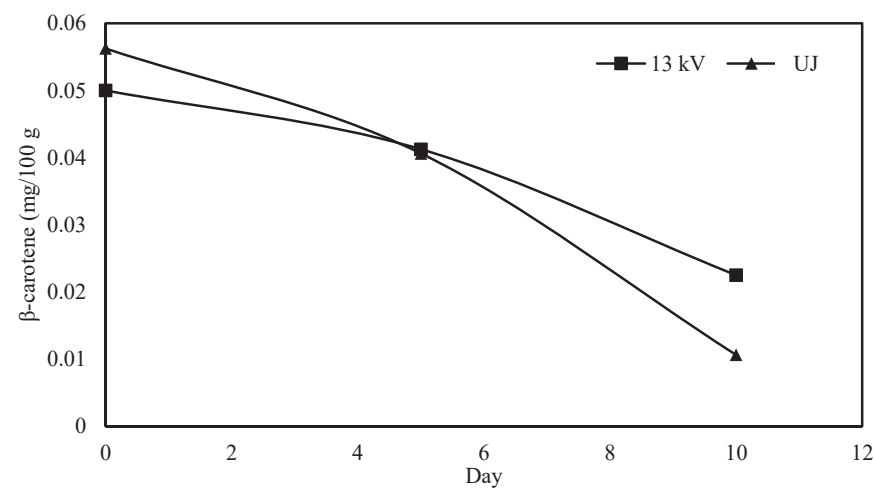

Figure 5: $\beta$-carotene content of PEF treated $(13 \mathrm{kV} / \mathrm{cm})$ and untreated juice $(\mathrm{UJ})$ at different days.
DPPH method is presented in Figure 6. The DPPH radical scavenging capacity of PEF treated juice was similar to that in untreated juice immediately after treatment. But, interestingly, it decreased at a greater pace in untreated juice than in PEF treated juice, at a later time.

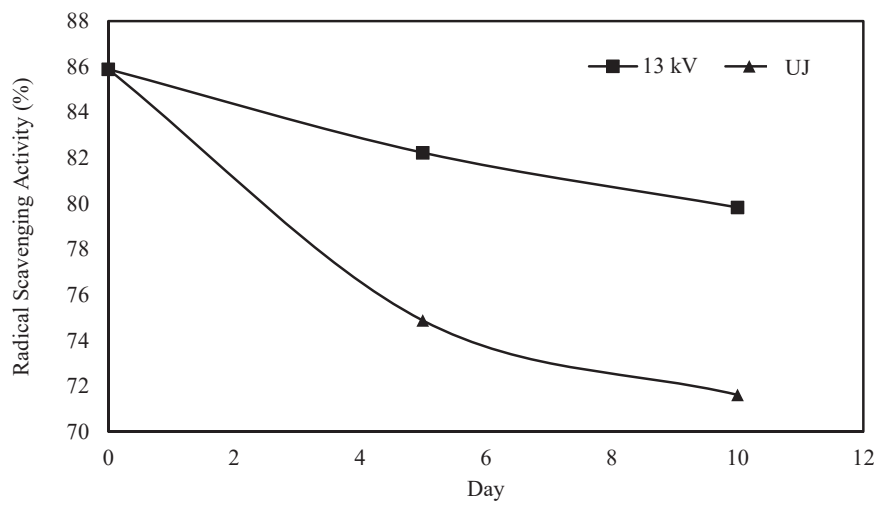

Figure 6: Radical scavenging activity of PEF treated $(13 \mathrm{kV} / \mathrm{cm})$ and untreated juice (UJ) during storage.

It is believed that most of the antioxidant capacity of fruits and vegetables come from the natural combination of different phytochemicals [43]. Some authors [12] tethered the decrease in antioxidant capacity of strawberry juice, over storage, to depletion in vitamin $\mathrm{C}$ and anthocyanin, whereas some others [44], showed a strict relationship between antioxidant capacity and ascorbic acid in blood orange juices. However, in their work, Gardner and his colleagues [16], suggested that less than $5 \%$ of the antioxidant activity of pineapple juice could be attributed to vitamin $\mathrm{C}$ as it does not belong to citrus fruit genre. Moreover, they implicitly indicated phenolic content to be responsible for antioxidant capacity of pineapple juice and our data of total phenolic content is in good agreement with their suggestion. As described in earlier section, TPC of untreated juice diminished at a faster rate than the PEF treated one which may well describe the quicker losing of radical savaging capacity of untreated pineapple. Likewise, $\beta$ carotene can also be held partially responsible for higher antioxidant capacity of PEF treated pineapple juice as it decreased at a slower pace than in untreated juice with time.

\section{Conclusion}

Present study showed that highest inactivation of microbe in PEF treated pineapple juice was observed at $13 \mathrm{kV} / \mathrm{cm}$ field strength. Since this applied field intensity failed to reach critical transmembrane potential, a moderate amount of bacteria survived or reversibly pored which helped them to grow in number after treatment. The phytochemicals studied in this experiment slightly altered during PEF treatment and degraded at the same pace of untreated juice over time except for total phenolics and $\beta$ carotene. TPC and $\beta$ carotene in untreated juice diminished at a higher rate than the treated juice, so was the antioxidant capacity. Hence, phenolics and $\beta$ carotene appeared to be a contributory factor to antioxidant capacity of pineapple juice. However, there was no perceptible change in temperature during PEF treatment. To conclude, 
PEF treatment could be a promising technology for preserving quality attributes of pineapple juice for an extended period of time, provided a field intensity above a certain critical value is applied.

\section{Acknowledgement}

The authors gratefully acknowledge the financial support provided by SUST (Shahjalal University of Science and Technology) Research Center, Sylhet, Bangladesh.

\section{References}

1. Collins AR, Harrington V (2002) Antioxidants; not the only reason to eat fruit and vegetables. Phytochem Rev 1: 167-174. Link: http://bit.ly/3casPUJ

2. Min S, Jin Z, Min S, Yeom H, Zhang Q (2003) Commercial-scale pulsed electric field processing of orange juice. J food sci 68: 1265-1271. Link: http://bit.ly/2uCVZek

3. Walkling-Ribeiro M, Noci F, Riener J, Cronin D, Lyng J, et al. (2009) The impact of thermosonication and pulsed electric fields on Staphylococcus aureus inactivation and selected quality parameters in orange juice. Food Bioproc Tech 2: 422-430. Link: http://bit.ly/2Vsh2LI

4. Bull MK, Zerdin K, Howe E, Goicoechea D, Paramanandhan P, et al. (2004) The effect of high pressure processing on the microbial, physical and chemical properties of Valencia and Navel orange juice. Innov Food Sci Emerg Technol 5: 135-149. Link: http://bit.ly/2w93NF7

5. Sanchez-Vega R, Mujica-Paz H, Marquez-Melendez R, Ngadi M, Ortega-Rivas (2009) Enzyme inactivation on apple juice treated by ultrapasteurization and pulsed electric fields technology. J Food Process Preserv 33: 486-499. Link: http://bit.ly/3aeZve9

6. Charles-Rodríguez A, Nevárez-Moorillón G, Zhang Q, Ortega-Rivas E (2007) Comparison of thermal processing and pulsed electric fields treatment in pasteurization of apple juice. Food and Bioproducts Processing 85: 93-97. Link: https://tinyurl.com/usf5wxw

7. Guo M, Jin TZ, Geveke DJ, Fan X, Sites JE, et al. (2014) Evaluation of microbial stability, bioactive compounds, physicochemical properties, and consumer acceptance of pomegranate juice processed in a commercia scale pulsed electric field system. Food Bioproc Tech 7: 2112-2120. Link: https://tinyurl.com/rjffbcb

8. Aronsson K, Rönner U, Borch E (2005) Inactivation of Escherichia coli, Listeria innocua and Saccharomyces cerevisiae in relation to membrane permeabilization and subsequent leakage of intracellular compounds due to pulsed electric field processing. Int J Food Microbiol 99: 19-32. Link: https://tinyurl.com/vn2b2zn

9. Toepfl S, Heinz V, Knorr D (2007) High intensity pulsed electric fields applied for food preservation. Chem Eng Process 46: 537-546. Link: https://tinyurl.com/uq5onbn

10. Kayalvizhi V, Pushpa A, Sangeetha G, Antony U (2016) Effect of pulsed electric field (PEF) treatment on sugarcane juice. J Food Sci Technol 53: 1371-1379. Link: https://tinyurl.com/w2azw4c

11. Sharma P, Bremer P, Oey I, Everett D (2014) Bacterial inactivation in whole milk using pulsed electric field processing. Int $\mathrm{J}$ Dairy 35: 49-56. Link: https://tinyurl.com/vxc5yzb

12. Odriozola-Serrano I, Soliva-Fortuny R, Martín-Belloso O (2008) Phenolic acids, flavonoids, vitamin $\mathrm{C}$ and antioxidant capacity of strawberry juices processed by high-intensity pulsed electric fields or heat treatments. Eur Food Res Technol 228: 239. Link: https://tinyurl.com/wwk4t|4

13. Ayhan Z, Zhang Q, Min D (2002) Effects of pulsed electric field processing and storage on the quality and stability of single-strength orange juice. J Food Protection 65: 1623-1627. Link: https://tinyurl.com/r5dlzqx
14. Aadil RM, Zeng XA, Ali A, Zeng F, Farooq MA, et al. (2015) Influence of different pulsed electric field strengths on the quality of the grapefruit juice. Int $\mathrm{J}$ Food Sci Technol 50: 2290-2296. Link: https://tinyurl.com/vpawqnr

15. Rattanathanalerk M, Chiewchan N, Srichumpoung W (2005) Effect of thermal processing on the quality loss of pineapple juice. J Food Eng 66: 259-265. Link: https://tinyurl.com/vx26q58

16. Gardner PT, White TA, McPhail DB, Duthie GG (2000) The relative contributions of vitamin $\mathrm{C}$, carotenoids and phenolics to the antioxidant potential of fruit juices. Food Chem 68: 471-474. Link: https://tinyurl.com/rddj8cz

17. Da Silva DI, Nogueira GD, Duzzioni AG, Barrozo MA (2013) Changes of antioxidant constituents in pineapple (Ananas comosus) residue during drying process. Ind Crops Prod 50: 557-562. Link: https://tinyurl.com/tauwn5d

18. Slinkard K, Singleton VL (1977) Total phenol analysis: automation and comparison with manual methods. Am J Enol Vitic 28: 49-55. Link: https://tinyurl.com/u6vxe2r

19. Chang CC, Yang MH, Wen HM, Chern JC (2002) Estimation of total flavonoid content in propolis by two complementary colorimetric methods. J Food Drug Anal 10: 178-182. Link: https://tinyurl.com/u4abvss

20. Ranganna S (1986) Handbook of analysis and quality control for fruit and vegetable products: Tata McGraw-Hill Education. Link: https://tinyurl.com/ ty2ytks

21. Biswas A, Sahoo J, Chatli M (2011) A simple UV-Vis spectrophotometric method for determination of $\beta$-carotene content in raw carrot, sweet potato and supplemented chicken meat nuggets. LWT-Food Scie Technol 44: 18091813. Link: https://tinyurl.com/svekgkd

22. Brand-Williams W, Cuvelier ME, Berset C (1995) Use of a free radical method to evaluate antioxidant activity. LWT- Food Scie Technol 28: 25-30. Link: https://tinyurl.com/uw4qzlb

23. García D, Gómez N, Mañas P, Raso J, Pagán R (2007) Pulsed electric fields cause bacterial envelopes permeabilization depending on the treatment intensity, the treatment medium $\mathrm{pH}$ and the microorganism investigated. Int $\mathrm{J}$ Food Microbiol 113: 219-227. Link: https://tinyurl.com/vaeuot4

24. Estifaee $P$, Su X, Yannam S, Rogers S, Thagard SM (2019) Mechanism of E. coli inactivation by direct-in-liquid electrical discharge plasma in low conductivity solutions. Scientific Rep 9: 2326. Link: https://tinyurl.com/wg2yghq

25. Pillet F, Formosa-Dague C, Baaziz H, Dague E, Rols MP (2016) Cell wall as a target for bacteria inactivation by pulsed electric fields. Scientific reports 6 : 19778. Link: https://tinyurl.com/wzc5zfa

26. Evrendilek GA, Jin Z, Ruhlman K, Qiu X, Zhang Q, et al. (2000) Microbial safety and shelf-life of apple juice and cider processed by bench and pilot scale PEF systems. Innov Food Sci Emerg Technol 1: 77-86. Link: https://tinyurl.com/qsbco45

27. Balasundram N, Sundram K, Samman S (2006) Phenolic compounds in plants and agri-industrial by-products: Antioxidant activity, occurrence, and potentia uses. Food chemistry 99: 191-203. Link: https://tinyurl.com/rgqkepe

28. Afanas' ev IB, Dcrozhko Al, Brodskii AV, Kostyuk VA, Potapovitch AI (1989) Chelating and free radical scavenging mechanisms of inhibitory action of rutin and quercetin in lipid peroxidation. Biochem Pharmacol 38: 1763-1769. Link: https://tinyurl.com/ro4t8qo

29. Zhang Y, Gao B, Zhang M, Shi J, Xu Y (2010) Pulsed electric field processing effects on physicochemical properties, flavor compounds and microorganisms of longan juice. J Food Process Preserv 34: 1121-1138. Link: https://tinyurl.com/s2hemvs

30. Liu F, Wang Y, Li R, Bi X, Liao X (2014) Effects of high hydrostatic pressure and high temperature short time on antioxidant activity, antioxidant compounds and color of mango nectars. Innov Food Sci Emerg Technol 21: 35-43. Link: https://tinyurl.com/rbezh3k

Citation: Yousuf A, Rahman MA, Uddin MR, Hoque MM, Sayem A, et al. (2020) Pineapple juice preservation by pulsed electric field treatment. Open J Biol Sci 5(1): 006-012. DOI: https://dx.doi.org/10.17352/ojbs.000016 
31. Minatel IO, Borges CV, Ferreira MI, Gomez HAG, Chen CYO, et al. (2017) Phenolic Compounds: Functional Properties, Impact of Processing and Bioavailability. Phenolic Compounds-Biological activity 236. Link: https://tinyurl.com/tm4zy8s

32. Macheix J, Fleuriet A, Billot J (1990) Phenolic compounds in fruit processing Fruit phenolics 1: 295-358.

33. Saci F, Meziant L, Louaileche $H$ (2015) Effect of storage time and temperature on the health-promoting substances and antioxidant activity of two commercial fruit based-beverages. Int J Bioinform Biomed Eng 1: 118-122. Link: https://tinyurl.com/wsof58u

34. Vieira F, Lourenço S, Fidalgo L, Santos S, Silvestre A, et al. (2018) Long term effect on bioactive components and antioxidant activity of thermal and high-pressure pasteurization of orange juice. Molecules 23: 2706. Link: https://tinyurl.com/vocf6h5

35. Owolade S, Akinrinola A, Popoola F, Aderibigbe O, Ademoyegun O, et al. (2017) Study on physico-chemical properties, antioxidant activity and shelf stability of carrot (Daucus carota) and pineapple (Ananas comosus) juice blend. Int J Food Res 24: 534-540. Link: https://tinyurl.com/shy4xvt

36. Cserhalmi Z, Sass-Kiss A, Tóth-Markus M, Lechner N (2006) Study of pulsed electric field treated citrus juices. Innov Food Innov Food Sci Emerg Technol 7: 49-54. Link: https://tinyurl.com/uhzb4zc

37. Min S, Jin ZT, Zhang QH (2003) Commercial scale pulsed electric field processing of tomato juice. Journal of agricultural and food chemistry 51 : 3338-3344. Link: https://tinyurl.com/t6jcovl
38. Sánchez-Moreno C, Plaza L, Elez-Martínez P, De Ancos B, Martín-Belloso O et al. (2005) Impact of high pressure and pulsed electric fields on bioactive compounds and antioxidant activity of orange juice in comparison with traditional thermal processing. J Agric Food Chem 53: 4403-4409. Link: https://tinyurl.com/wjkk9es

39. Rodriguez-Amaya DB (1997) Carotenoids and food preparation: the retention of provitamin $A$ carotenoids in prepared, processed and stored foods. John Snow Incorporated/OMNI Project Arlington, VA. Link: https://tinyurl.com/slsgdy3

40. Van den Berg H, Faulks R, Granado HF, Hirschberg J, Olmedilla B, et al. (2000) The potential for the improvement of carotenoid levels in foods and the likely systemic effects. J Sci Food Agric 80: 880-912. Link: https://tinyurl.com/vo34x3d

41. Cortés C, Torregrosa F, Esteve MJ, Frígola A (2006) Carotenoid profile modification during refrigerated storage in untreated and pasteurized orange juice and orange juice treated with high-intensity pulsed electric fields. J Agric Food Chem 54: 6247-6254. Link: https://tinyurl.com/vgwqpwc

42. Antonio J, Melendez-Mart N, Isabel M, Francisco J (2007) Review: Analysis of carotenoids in orange juice. J Food Compos Anal 20: 638-649. Link: https://tinyurl.com/rqynoer

43. Eberhardt MV, Lee CY, Liu RH (2000) Nutrition: Antioxidant activity of fresh apples. Nature 405: 903

44. Arena E, Fallico B, Maccarone E (2001) Evaluation of antioxidant capacity of blood orange juices as influenced by constituents, concentration process and storage. Food Chemistry 74: 423-427. Link: https://tinyurl.com/vncmpq3

\section{Discover a bigger Impact and Visibility of your article publication with} Peertechz Publications

\author{
Highlights \\ * Signatory publisher of ORCID \\ * Signatory Publisher of DORA (San Francisco Declaration on Research Assessment) \\ * Articles archived in worlds' renowned service providers such as Portico, CNKI, AGRIS, \\ TDNet, Base (Bielefeld University Library), CrossRef, Scilit, J-Gate etc. \\ * Journals indexed in ICMJE, SHERPA/ROMEO, Google Scholar etc. \\ - OAI-PMH (Open Archives Initiative Protocol for Metadata Harvesting) \\ * Dedicated Editorial Board for every journal \\ * Accurate and rapid peer-review process \\ * Increased citations of published articles through promotions \\ * Reduced timeline for article publication \\ Submit your articles and experience a new surge in publication services \\ (https://www.peertechz.com/submission).
}

Peertechz journals wishes everlasting success in your every endeavours.

Copyright: @ 2020 Yousuf A, et al. This is an open-access article distributed under the terms of the Creative Commons Attribution License, which permits unrestricted use, distribution, and r eproduction in any medium, provided the original author and source are credited.

Citation: Yousuf A, Rahman MA, Uddin MR, Hoque MM, Sayem A, et al. (2020) Pineapple juice preservation by pulsed electric field treatment. Open J Biol Sci 5(1): 006-012. DOI: https://dx.doi.org/10.17352/ojbs.000016 